\title{
Previsão legal da suspensão condicional do processo como ferramenta de efetividade da Lei Maria da Penha
}

\section{Legal provision of Conditional Suspension of the procecess as an Efective tool for Maria da Penha ACT}

\author{
Márcia Haydée Porto de Carvalho \\ Maicy Milhomem Moscoso Maia ${ }^{2}$
}

\begin{abstract}
RESUMO
Este artigo propõe a inclusão do instituto da suspensão condicional do processo no bojo da Lei $\mathrm{n}^{\mathrm{o}}$. 11.340/2006, mais conhecida como Lei Maria da Penha, a partir da promoção de uma alteração legislativa na referida norma, impeditiva da aplicação daquele instituto às ações penais sobre violência doméstica contra a mulher. Não se pretende esgotar o assunto, mas fortalecer essa discussão, trazendo argumentos favoráveis ao emprego da suspensão condicional do processo no âmbito da violência doméstica contra a mulher, pois, recentes estudos apontam para a inefetividade da forma como os crimes desta natureza são processados e julgados. Busca-se, portanto, através da revisão bibliográfica, coleta de dados em pesquisas de cunho quali-quantitativo de base empírica e pesquisa documental na legislação pertinente ao tema, delinear a suspensão condicional do processo, demonstrar a sua aplicabilidade à Lei Maria da Penha e às tendências relacionadas à Justiça Penal Consensual, assim como apresentar mecanismos que evitem o desvirtuamento do instituto.
\end{abstract}

\section{PALAVRAS-CHAVE:}

Violência doméstica contra a mulher. Justiça Criminal Consensual. Suspensão condicional do processo.

\footnotetext{
ABSTRACT

This article proposes the inclusion of the institute of conditional suspension of the process within the scope of Law nº 11.340/2006, better known as the Maria da Penha Law, from the promotion of a legislative change in the referred rule, restricted to the application of that

${ }^{1}$ Possui graduação em Ciências Econômicas pela Universidade Federal do Maranhão -UFMA (1997), graduação em Direito pela UFMA (1993), mestrado em Direito pela Pontifícia Universidade Católica de São Paulo (2001) e doutorado em Direito pela Pontifícia Universidade Católica de São Paulo (2005) e Especialização em Altos Estudos de Política e Estratégia pela Escola Superior de Guerra. Atualmente exerce o cargo de Professor Associado I da UFMA, lecionando na graduação em Direito e no Mestrado em Direito e Instituições do Sistema de Justiça, professora pesquisadora em Direito do Centro Universitário do Maranhão e promotora de justiça no Maranhão, titular da $6^{\text {a }}$ Promotoria de Justiça Especializada- $2^{\circ}$ Promotor de Justiça Militar do termo judiciário de São Luís da Comarca da Ilha de São Luís/MA. Tem experiência na área de Direito, com ênfase em Direito Constitucional, trabalhando principalmente com os seguintes temas: Instituições dos Sistemas de Justiça, Hermenêutica Constitucional, Controle de Constitucionalidade e Direitos Fundamentais. Em 2019 foi admitida como investigadora no Centro de Estudios Políticos y Constitucionales (Madrid/Espanha).

2 Bacharel em Direito pela Universidade Federal do Maranhão (2011). Advogada licenciada pela OAB/MA. Mestre em Direito e Instituições do Sistema de Justiça pela Universidade Federal do Maranhão (2020). Atualmente exerce o cargo de Assessora de Promotor de Justiça no Ministério Público do Maranhão.
} 
institute in relation criminal actions against the woman. The present study does not intend to exhaust the subject, but to strengthen this discussion, bringing favorable arguments to the application of the conditional suspension of the process in the scope of domestic violence against the woman, because recent studies point to the ineffectiveness of the way crimes of this nature are prosecuted and judged. Therefore, through bibliographic review, data collection in empirical qualitative and quantitative research and documentary research in the relevant legislation is sought, delineating the process's conditional suspension, demonstrating its applicability to the Maria da Penha Act and to trends related to the Consensual Criminal Justice, as well as to present mechanisms that avoid the distortion of the institute.

\section{KEYWORDS:}

Domestic violence against women. Consensual Criminal Justice. Conditional suspension of the process.

\section{INTRODUÇÃO}

A violência doméstica como fenômeno social é algo bastante complexo e o tratamento jurídico desta questão tem se mostrado, ao longo dos anos, como um tema desafiador, pois, inobstante as muitas políticas públicas destinadas à sua erradicação e as várias ações do poder judiciário e outras instituições do sistema de justiça, a incidência desta espécie de crime ainda é bastante vigorosa. Em termos sociais, a complexidade desta questão envolve os conceitos de patriarcado, gênero e dominação, que são exaustivamente trabalhados por renomados autores, como Bourdieu (2012) e Saffioti (1995).

O patriarcado é a mais antiga forma de dominação conhecida pela humanidade. Esta forma de dominação estabelece-se através de esquemas do inconsciente sexuado, que se reproduz por meio de estruturas históricas e altamente diferenciadas que fazem com que os indivíduos experienciem e aprendam as oposições ${ }^{3}$ destes espaços de reprodução de poder. Essas diferenciações destacam em cada indivíduo, homem ou mulher, “[...] os signos exteriores mais proeminentes e conformes à definição social de 'feminino' e 'masculino', ou estimulam

\footnotetext{
${ }^{3}$ Oposições que sempre guardam correspondência com a distinção fundamental da estrutura feminino x masculino, como: forte e fraco, grande e pequeno, pesado e leve, gordo e magro, etc.
} 
as práticas condizentes com o seu sexo, proibindo ou desencorajando as condutas impróprias, especialmente no que diz respeito ao outro sexo [...]” (BOURDIEU, 2012, p. 124-135).

Neste sentido, o gênero refere-se à construção social do masculino e do feminino, modelos ideologicamente propagados como opostos e, ao mesmo tempo, complementares. As relações de gênero se configuram tanto como categorias de análise, quanto processos sociais e são, fundamentalmente, relacionais, determinando processos complexos e instáveis. Consoante Saffioti e Almeida (1995, p. 196-197)

As correntes feministas anticartesianas defendem que homem e mulher são categorias diferentes e não contrárias/excludentes. Isto significa que a desejada igualdade entre homens e mulheres se consubstancia no reconhecimento das suas diferenças e limitações, e que o poder em sua forma ideal deve ser exercido de maneira não arbitrária, democraticamente, fluindo livremente do eixo do gênero entre homem e mulher e vice-versa.

Os conceitos de patriarcado, gênero e dominação delineiam o cenário em que a violência doméstica se desenrola. Nos últimos anos, muitas pesquisas sobre violência doméstica, sob diversos recortes, foram realizadas. Destas pesquisas, destaca-se as de Souza (2016) e Maia (2020), que partem da análise de ações penais que tem por objeto o processamento e o julgamento de crimes praticados sob os auspícios da violência doméstica e cujas conclusões são negativamente impactantes: grande parte dos processos judiciais não são efetivos porque são fulminados pela prescrição penal.

Ao mesmo tempo, o Instituto de Pesquisa Econômica Aplicada (IPEA), nos Atlas da Violência dos anos de 2017, 2018 e 2019, registrou que a taxa de ocorrência de crimes praticados contra mulheres é crescente e que, grande parte destes delitos são cometidos no contexto de um longo ciclo de violência doméstica, ou seja, após agressões continuadas suportadas silenciosamente pelas vítimas.

Segundo o Atlas da Violência 2019 do IPEA (2019, p. 35):

[...] houve um crescimento dos homicídios femininos no Brasil em 2017, com cerca de 13 assassinatos por dia. Ao todo, 4.936 mulheres foram mortas, o maior número registrado desde 2007 [...] A magnitude do fenômeno e de suas variações pode ser mais bem aferida em termos da taxa de homicídio por grupo de 100 mil mulheres, que permite maior comparabilidade temporal e entre as diferentes unidades federativas. Entre 2007 e 2017 houve aumento de 20,7\% na taxa nacional de homicídios de mulheres, quando a mesma passou de 3,9 para 4,7 mulheres assassinadas por grupo de 100 mil mulheres. Nesse período, houve crescimento da taxa em 17 Unidades da Federação. Já no recorte de 2012 a 2017, observamos aumento de 1,7\% na taxa 
nacional e um aumento maior ainda de 5,4\% no último ano, período em que se verificam taxas ascendentes em 17 UFs em relação a 2016. Considerando o período decenal, Rio Grande do Norte apresentou o maior crescimento, com variação de $214,4 \%$ entre 2007 e 2017, seguido por Ceará (176,9\%) e Sergipe (107,0\%). Já no ano de 2017, o estado de Roraima respondeu pela maior taxa, com 10,6 mulheres vítimas de homicídio por grupo de 100 mil mulheres, índice mais de duas vezes superior à média nacional $(4,7)$. A lista das unidades federativas onde houve mais violência letal contra as mulheres é seguida por Acre, com taxa de 8,3 para cada 100 mil mulheres, Rio Grande do Norte, também com taxa de 8,3, Ceará, com taxa de 8,1, Goiás, com taxa de 7,6, Pará e Espírito Santo com taxas de 7,5.

Observa-se ainda que todos os anos são intensificadas as políticas de divulgação da violência de gênero como conduta socialmente indesejada, recursos financeiros e humanos são destinados para o aparelhamento dos Juizados Especializados em Violência Doméstica, assim como, ano após ano, endurece-se ainda mais a legislação penal, o que, de acordo com as pesquisas, não tem demonstrado efeitos concretos na realidade quanto ao enfrentamento da questão, já que as taxas de crimes contra mulheres só crescem.

Na verdade, os dados indicam a necessidade de otimização da legislação voltada para a coerção dos delitos cometidos em ambiente doméstico. Recentemente, pode-se observar um movimento na legislação penal brasileira que a tem conduzido, pouco a pouco, à expansão dos espaços de consenso, com a inserção de ferramentas de justiça criminal negocial ou consensual. A exemplo disso, tinha-se a pretensão de inclusão do art. 395-A ao Código de Processo Penal, através das alterações promovidas pela Lei $\mathrm{n}^{\circ}$. 13.964, de 24 de dezembro de 2019. O referido dispositivo, se aprovado, permitiria que, no interregno compreendido entre o recebimento da peça acusatória e o início da instrução penal, o Ministério Público, o querelante ou o acusado, poderiam pleitear, mediante acordo penal, a aplicação imediata das penas.

Com destino diverso do art. 395-A, o art. 28-A foi aprovado pelo Congresso Nacional e sancionado, inaugurando no diploma processual penal a possibilidade de celebração de Acordo de Não Persecução Penal, proposto pelo Ministério Público, desde que necessário e suficiente para a reprovação e prevenção do crime. Este dispositivo, todavia, é taxativo ao, em seu $\S 2^{\circ}$, inc. IV, proibir a aplicação do instituto na hipótese de crimes cometidos no âmbito da violência doméstica ou familiar, ou praticados contra a mulher por razões da condição de sexo feminino (gênero). Inobstante a citada restrição, o presente estudo compreende estas decisões legislativas como tendências do atual processo penal brasileiro e que visam garantir maior celeridade e efetividade às demandas criminais. É necessário fazer um exercício argumentativo de enquadramento da questão da violência doméstica ao cenário da justiça criminal negocial e 
retirar dele o melhor que se pode oferecer como solução para o problema da inefetividade judicial neste âmbito.

Diante dos resultados que se tem observado no desempenho do poder judiciário na administração da justiça quanto aos casos de violência doméstica, a suspensão condicional do processo, uma fórmula já conhecida do ordenamento jurídico brasileiro, mostra-se como uma alternativa de justiça criminal consensual que pode servir como instrumento de aprimoramento da legislação destinada à proteção da mulher.

\section{A SUSPENSÃO CONDICIONAL DO PROCESSO}

A suspensão condicional do processo está prevista na Lei no $.9 .099 / 1995$, que trata sobre os Juizados Especiais Cíveis e Criminais ${ }^{4}$. O instituto pode ser definido como a suspensão da ação penal com a anuência do réu, após o recebimento da peça acusatória, desde que aquele preencha alguns requisitos e cumpra as condições impostas durante um determinado período de tempo, prefixado que, vencido, ensejará a extinção da punibilidade, quando não houver motivo para a revogação do benefício.

O art. 89 desta norma estabelece que, nos crimes em que a pena mínima cominada for igual ou inferior a 01 (um) ano, o Ministério Público, ao oferecer a denúncia, poderá propor a suspensão do processo, por 02 (dois) a 04 (quatro) anos, desde que o acusado não esteja sendo processado ou não tenha sido condenado por outro crime, presentes os demais requisitos que autorizariam a suspensão condicional da pena, nos termos do que dispõe o art. 77 do Código Penal.

Os demais requisitos necessários para possibilitar a suspensão condicional da pena, referenciados pelo art. 89 da Lei $n^{\circ} .9 .099 / 1995$ e previstos no art. 77 do Código Penal, são circunstâncias exigidas para a suspensão condicional da pena privativa de liberdade: a) o

\footnotetext{
${ }^{4}$ A Lei 9.099/1995 foi criada sob a égide da desburocratização do processo penal, trazendo institutos como a transação penal, a composição civil e a suspensão condicional do processo, abrindo espaço para a justiça criminal consensual.
} 
condenado não ser reincidente em crime doloso; b) a culpabilidade, os antecedentes, a conduta social e personalidade do agente, bem como os motivos e as circunstâncias autorizem a concessão do benefício; c) não ser indicada ou cabível a substituição prevista no art. 44 do Código Penal (art. 77, inc. III, do Código Penal).

No que diz respeito a este último ponto, ou seja, o art. 77, inciso III do Código Penal, Grinover (1995) adverte que ele é incompatível em relação à suspensão condicional do processo, concluindo que mesmo quando for incabível a substituição da pena prevista no art. 44 do CP, ainda assim, poderá haver aplicação do instituto.

Assim, uma vez recebida a denúncia e aceita a proposta de suspensão do processo pelo acusado e seu defensor, na presença do Juiz, este poderá homologar o acordo e suspender o processo, submetendo o acusado a período de prova, sob as seguintes condições obrigatórias apresentadas pelo membro do Ministério Público: a) reparação do dano, salvo impossibilidade de fazê-lo; b) proibição de frequentar determinados lugares; c) proibição de ausentar-se da comarca onde reside, sem autorização do Juiz; d) comparecimento pessoal e obrigatório a juízo, mensalmente, para informar e justificar suas atividades.

Analisando as especificidades do caso concreto, o magistrado poderá estabelecer outras condições para vincular a suspensão condicional do processo, desde que adequadas ao fato e à situação pessoal do acusado. Constituem exemplos de condições facultativas:

Frequentar curso de habilitação profissional ou de instrução escolar; atender aos encargos da famílias; submeter-se a tratamento de desintoxicação; frequentar cursos de reabilitação de alcoolismo; submeter-se a tratamento médico ou psicológico quando haja indicação de sua necessidade e eficácia; entregar ao Estado ou Instituições de auxílio comunitário "cestas básicas" de alimentos ou medicamentos; não acompanhar, alojar ou receber certas pessoas. (MIRABETE, 1997, p. 162).

Segundo Carvalho (2010), como a homologação depende da aceitação do réu, fica evidenciado o caráter de bilateralidade do instituto.

Para que o período de prova revista-se do caráter educativo e corretivo, característico da prevenção geral, recomenda-se a existência de um plano de adaptação social e submissão do beneficiário a uma vigilância não ostensiva, objetivando o desenvolvimento de sua responsabilidade social (BITENCOURT, 2005, p. 155). Não teria sentido impor condições e deixar de fiscalizar o seu cumprimento. 
A suspensão condicional do processo, na qualidade de instituto despenalizador, apresenta-se como uma alternativa às penas restritivas de liberdade, pois, como reconhece Braga Filho (2006) evita a aplicação da pena, mas sem esvaziar o caráter ilícito da conduta típica.

Além disso, o benefício poderá ser revogado: a) se, no curso do prazo, o beneficiário vier a ser processado por outro crime ou não efetuar, sem motivo justificado, a reparação do dano; b) se o beneficiário vier a ser processado, no curso do prazo, por contravenção, ou descumprir qualquer outra condição imposta. Registra-se que, durante o prazo em que viger o benefício não corre o prazo prescricional e, caso o réu não aceite a proposta de suspensão condicional do processo, o processo prosseguirá, seguindo a tramitação normal. Em relação à aceitação do benefício pelo réu, Giuliani (2014) explica que em se tratando de justiça negociada, a liberdade de escolha deve ser a tônica do procedimento, pois dela depende a intervenção penal melhor do que aquela prevista ou imposta pela lei nos ritos tradicionais.

A suspensão condicional do processo não envolve a confissão de culpa por parte do réu. Ele apenas não contesta a acusação. Nas palavras de Braga Filho (2006) isso é tão certo que, uma vez revogado o benefício, a tramitação do processo marchar.

Como já se disse, expirado o período de prova sem revogação, a autoridade judicial deve declarar extinta a punibilidade (art.89, $\S 5^{\circ}$, da Lei $n^{\circ}$ 9.099/95, determinando o arquivamento do processo. Todavia, a extinção da punibilidade fundada nesse dispositivo legal pressupõe o cumprimento por parte do beneficiário de todas as condições estabelecidas no sursis processual (CARVALHO, 2010).

\section{A ADEQUAÇÃO DA SUSPENSÃO CONDICIONAL DO PROCESSO À LEI MARIA DA PENHA}

A Lei $n^{\circ} .11 .340 / 2006$, desde a sua gênese, contou com o art. 41, que proibia a aplicação da Lei dos Juizados Especiais (Lei nº 9.099/1995), independentemente da pena prevista. A existência deste dispositivo gerou uma série de divergências, uma vez que, desde a publicação 
da Lei $n^{\circ}$. 9.099/1995, os institutos da transação penal, composição civil e suspensão condicional do processo vinham sendo aplicados aos casos de violência doméstica, desde que cumpridos os requisitos legais.

Sob o argumento de ofensa ao princípio da igualdade, a questão chegou ao Supremo Tribunal Federal - STF através da Ação Direta de Constitucionalidade no 19 (ADC Nº 19) e teve como Relator o Ministro Marco Aurélio. Referida Ação foi julgada pelo Plenário do STF em 09/02/2012, quando decidiu-se, por votação unânime, pela constitucionalidade dos arts. $1^{\circ}$, 33 e 41, todos da Lei $n^{\circ}$. 11.340/2006, promovendo a uniformização judicial da interpretação dos referidos artigos. O voto da Ministra Rosa Weber é o que melhor enfrenta os argumentos de desigualdade arbitrária direcionados art. 41 da Lei Maria da Penha, ratificando o entendimento daquela Corte, de que o citado art. 41 encontra-se em perfeita consonância com o art. 98, inc. I e art. 226, § 8 , ambos da Constituição Federal.

Compreende-se melhor o posicionamento do STF quando se percebe o quadro de completo descaso que se vinha adotando nos Juizados Especiais Criminais em relação à violência doméstica contra a mulher.

Carvalho (2015) observa que, de fato, no interregno compreendido entre a edição da 1.999/1995 e a Lei n ${ }^{\circ}$. 11.340/2006, os institutos da composição civil e da transação penal foram desvirtuados, especialmente nos casos de violência doméstica contra a mulher, transformado o primeiro em pedido de perdão do agressor para a vítima, que na grande maioria dos casos era aceito, e o segundo, reduzido ao pagamento de cestas básicas ou prestação isolada de serviços à comunidade. Segundo a autora, o uso inadequado destes institutos os tornava inefetivos, invisibilizavam as vítimas e produziam a sensação de impunidade.

Entende-se, todavia, que tais consequências negativas não puderam ser vislumbradas quanto ao instituto da suspensão condicional do processo, mas o Supremo Tribunal Federal acabou por excluir a possibilidade de aplicação de todos os institutos despenalizadores nas ações penais de violência doméstica.

Com essa decisão do STF, os Projetos de Lei que tramitavam no Congresso Nacional destinados à alteração da Lei Maria da Penha para inserção de meios de justiça criminal 
consensual foram arquivados, a exemplo do PL No. 4.501/12, de autoria da deputada Aline Corrêa, arquivado em 31/01/2015.

Carvalho (2015) informa que após o julgamento da ADC No .19 e as críticas veiculadas por vários órgãos e instituições, o poder legislativo postergou a apresentação do parecer da relatora do citado projeto na Câmara dos Deputados, deixando de examiná-lo com a devida relevância, sob o argumento de que o STF já havia resolvido a questão. Ao agir dessa forma, diz a autora, o Poder Legislativo abriu mão da sua legitimidade democrática para discutir e analisar com maior acuidade a possibilidade de aplicação da suspensão condicional do processo, a partir de uma alteração legislativa à Lei Maria da Penha.

Carvalho (2015, p. 160) esclarece que

[...] o STF julgou sem levar em conta a necessidade da existência, nos casos de violência doméstica contra a mulher, de uma abertura ao diálogo e à conciliação, devidamente regrada por lei e controlada pelo Judiciário, como a possibilidade de suspensão condicional do processo quando o ciclo da violência ainda não se instalou por estar no seu início ou nos casos em que, passados os momentos iniciais da ocorrência do fato, o réu e a vítima já se reconciliaram. Portanto, é preciso que o Poder Legislativo exerça suas funções. Se é verdade que o STF tem a última palavra quanto à interpretação constitucional, essa última palavra deve ser entendida como provisória. Isso porque o STF também pode errar, cabendo ao Legislativo, enquanto órgão cujos integrantes foram eleitos pelo povo e, portanto, mais legitimado democraticamente, corrigir o problema, recriando o instituto para os casos de violência doméstica contra a mulher, o qual foi descartado por aquele órgão, se tal medida lhe parecer constitucional, instituindo, assim, a possibilidade de um diálogo entre os poderes, já que sua decisão estará novamente sujeita a controle de constitucionalidade, em prol da justiça e da democracia.

Na maioria das democracias constitucionais, a interpretação da Constituição envolve o Poder Judiciário (tipicamente a Suprema Corte ou Corte Constitucional) (MARMOR, 2005). No Brasil não é diferente. Enquanto responsável por realizar a guarda da Constituição, o Supremo Tribunal Federal tem competência para dar a última palavra sobre interpretação constitucional nas ações diretas de inconstitucionalidade, ações declaratórias de constitucionalidade, arguição de descumprimento de preceito fundamental e ações de inconstitucionalidade por omissão (em sede de controle de constitucionalidade concentrado) e recurso extraordinário (em situação de controle de constitucionalidade difuso).

No modelo brasileiro, portanto, cabe ao Supremo Tribunal Federal o papel, que, para Andrei Marmor (2005, p. 140) significa, de 
[...] resolver questões de profunda importância moral e política, com base em uma orientação textual muito limitada, resultando em decisões jurídicas que devem durar por décadas e são praticamente quase impossíveis de mudar pelo processo democrático regular.

Entretanto, as diferentes Teorias do Diálogo entre os Poderes rechaçam a ideia do monopólio judicial na interpretação da constituição, a qual é e deve ser exercida pelos demais poderes, e defendem que não existe uma última palavra ou, pelo menos de que a Corte Constitucional a detenha por meio do controle de constitucionalidade.

Supondo que há uma última palavra e que esta pertence à Corte Constitucional, essa última palavra deve ser entendida como "última palavra provisória", que não impede novas rodadas procedimentais, em que se produza um diálogo entre o Poder Judiciário e Legislativo (MENDES, 2011).

Com o advento da Lei $n^{\circ}$. 9.099/1995, o ordenamento criminal brasileiro, com clara influência do modelo processual penal norte-americano, vem buscando a ampliação do espaço de consenso em relação ao espaço de conflito, na tentativa de tornar-se mais célere e efetivo. Gomes (1997) argumenta que no modelo justiça criminal inaugurado pela Lei dos Juizados Especiais, a resposta jurídica adequada para cada conduta desviada, deve ser justa e útil, a partir do critério do potencial ofensivo do delito (menor, médio e maior potencial ofensivo). Esse parâmetro demanda que a política criminal defina para cada uma destas espécies de criminalidade, respostas qualitativas e quantitativas diversas, com instrumentos, processos e procedimentos diferentes, assim como a clara demarcação entre o espaço de consenso do espaço de conflito.

Gomes (1997) qualifica o espaço de consenso como aquele destinado à pequena e média criminalidade, cuja prioridade é a ressocialização do autor do fato delituoso, sendo possível a flexibilização de alguns direitos e garantias fundamentais, tais como a presunção de inocência, a igualdade de oportunidades, a busca pela verdade real, etc. O escopo é eliminar conflitos desnecessários para atender os fins do processo e a função ressocializadora da pena, fazendo com que o autor do fato delitivo aceite de forma mais ativa a responsabilidade por seus atos.

O espaço de conflito, segundo Gomes (1997), por seu turno, tem como características a contrariedade e o antagonismo, o indispensável cumprimento dos direitos e garantias fundamentais, tais como a presunção de inocência, o devido processo legal, a busca pela 
verdade material, o duplo grau de jurisdição, entre outros. E continua o autor, dizendo que o conflito deve estar reservado para a perseguição da criminalidade de alta reprovabilidade, bastante presente em crimes dolosos, praticados mediante violência ou grave ameaça e através de atos reiterados, com grande repercussão socioeconômica, assim como outros crimes de elevada danosidade.

Para Giuliani (2014), a tendência da justiça negociada ou consensual encontra-se no nicho das medidas alternativas do processo penal, prevendo penas diferenciadas para crimes que afetam de forma mais branda determinados bens jurídicos, buscando a diminuição do uso da pena privativa de liberdade e reinserir a vítima no processo penal, devolvendo-lhe parcialmente o conflito que a atinge. Desta forma, a autora defende que a função prioritária da justiça negociada e consensual é promover o reavivamento da resposta social, para torná-la mais célere, eficiente e efetiva, atendendo as necessidades reais das relações sociais da atualidade.

Pesquisas recentes apontam que, em se tratando de violência doméstica, o sistema penal não tem oferecido respostas satisfatórias. Souza (2016) dedicou-se à análise da aplicação das sanções da Lei $n^{\circ}$. 11.340/2006 nas 03 (três) Varas de Juizado de Violência Doméstica e Familiar Contra a Mulher (VJVDFCM) da Comarca de Belém/PA, debruçando-se sobre os processos arquivados ao longo do ano de 2011, oportunidade em que constatou que, apesar da grande expectativa punitiva gerada com o advento da Lei Maria da Penha e o seu paulatino endurecimento, a realidade belemense revelou um número baixo de sentenças condenatórias (apenas 10\% do número total) (SOUZA, 2016, p. 174). Tal resultado confirma a hipótese de que, mesmo diante do expresso rigor da Lei $\mathrm{n}^{\circ}$. 11.340/2006, o Poder Judiciário não tem aplicado severas sanções (SOUZA, 2016, p. 171). Na verdade, a citada pesquisadora deparouse com um cenário em que a grande maioria dos processos era arquivada por questões técnicas e processuais, como a prescrição penal, constatada em $46 \%$ dos processos analisados (SOUZA, 2016, p. 176), causas essas alheias ao cotidiano das vítimas, identificando a ocorrência da lógica da "trivialização do conflito"5.

\footnotetext{
5 A trivialização do conflito observada na pesquisa de Souza (2016) está consubstanciada em decisões de arquivamento que são proferidas sem que haja uma única audiência, ainda no despacho de recebimento da denúncia ou queixa, originados de problemas que ocorrem desde a distribuição dos processos, quando estes são enviados para Varas erradas ou sem constar informações essenciais como o endereço das partes para citação/intimação (SOUZA, 2016, p. 173).
} 
A pesquisa de Souza (2016) examinou uma amostra de 152 (cento e cinquenta e dois processos) das VJVDFCM da Comarca de Belém/PA, com o objetivo de averiguar indicadores como: o tempo de duração na fase do inquérito policial; o percentual de representação da vítima ou oferecimento de queixa-crime; a relação entre agressor e ofendida; a atuação das partes durante a tramitação do processo; o percentual de ocorrência de transação penal, suspensão condicional da pena, reparação do dano, decadência, desistência, retratação, renúncia; o índice de reincidência dos agressores, dentre outros pontos que tornaram a pesquisa de Souza (2016) bastante relevante para o entendimento da violência doméstica, sob o viés jurídico.

Mais recentemente, Maia (2020) pesquisou as ações penais de competência da Vara Especial de Violência Doméstica e Familiar Contra a Mulher (VEVDFCM) da Comarca de São Luís/MA, sob o viés da prescrição e da efetividade, durante os anos de 2014 e 2018, oportunidade em que constatou que: a) do total de 916 (novecentas e dezesseis) sentenças penais analisadas $^{6}, 243$ (duzentas e quarenta e três) continham absolvição de crimes, 348 (trezentas e quarenta e oito) apresentavam condenação de delitos e 502 (quinhentas e duas) tinham prescrições penais reconhecidas; b) do total de 502 (quinhentas e duas) prescrições, 161 (cento e sessenta e uma) ocorreram após a prolatação da sentença condenatória, enquanto que, o restante, ou seja 341 (trezentos e quarenta e uma) se deram antes do proferimento da sentença condenatória. Isto significa que, mesmo havendo condenação (348 condenações), mais da metade (em 161 casos), 46,26\% (quarenta e seis vírgula vinte e seis por cento) deste montante foi alcançado pela prescrição. Em resumo, Maia (2020) concluiu que, na Vara de Violência Doméstica estudada, na grande maioria dos casos, quando a prescrição penal não atinge o jus puniendi antes do trânsito em julgado da sentença, ela alcança a pretensão executória do Estado.

\footnotetext{
${ }^{6}$ Importante destacar a opção metodológica feita pela autora, que observou a ocorrência de peças acusatórias contendo mais de um delito e, por conta disso, foram contabilizadas separadamente as absolvições, condenações e prescrições, a exemplo de casos em que em uma mesma sentença se observou a absolvição de um crime e condenação de outro ou mesmo, o reconhecimento da ocorrência da prescrição em relação a um crime e o prosseguimento do processo no que se refere ao outro crime. Isso também explica por que, somando-se os valores referentes às ações penais encontradas $(243+348+502)$, o resultado (1.093) é bem superior ao total de ações penais analisadas (916), já que os crimes foram considerados separadamente, ainda que constantes da mesma sentença.
} 


\section{NECESSIDADE DE ALTERAÇÃO LEGISLATIVA DA LEI MARIA DA PENHA PARA INCLUIR A SUSPENSÃO CONDICIONAL DO PROCESSO}

A realidade apresentada pelas coletas de dados locais de Souza (2016) e Maia (2020) descortinam uma realidade que é pouco divulgada pelos órgãos públicos: a incapacidade das instituições do sistema de justiça em lidar efetivamente com as demandas oriundas da violência doméstica contra a mulher, demandando a reflexão e discussão sobre outros meios que possibilitem a entrega da resposta justa, útil e célere à sociedade.

Propõe-se a alteração do art. 41, da Lei Maria da Penha para que ela abrigue a possibilidade de realização da suspensão condicional do processo, instituto este que deve ser adequado às especificidades que as demandas que envolvem violência doméstica exigem.

Contra o argumento de que esta abordagem já foi testada ${ }^{7}$, mas sem êxito, sustenta-se, com base em Carvalho (2015) que essa posição é falaciosa, pois, a suspensão condicional do processo sequer chegava a ser aplicada, já que os processos de violência doméstica, em sua grande maioria, encerravam-se com a composição civil dos danos ou com a transação penal. Neste sentido, não se poderia falar em desvirtuamento do instituto, sendo a resistência contra ele, infundada.

Nesse passo, é preciso lembrar ainda que a suspensão condicional do processo impõe a aplicação das mesmas condições do sursis, geralmente atribuídas em caso de condenação nos casos de crimes em situação de violência doméstica contra a mulher com pena mínima em abstrata igual ou inferior a 01 (um) ano, todavia de modo muito mais rápido. Em outros termos, não é preciso chegar até o final do processo para se obter os mesmos resultados e de modo muito mais demorado.

Outro argumento que corrobora para a aplicação da suspensão condicional do processo à Lei Maria da Penha refere-se à maior incidência dos crimes de "menor potencial ofensivo"

\footnotetext{
${ }^{7}$ Durante os anos de 1995 (ano da criação da Lei dos Juizados Especiais) até fevereiro do ano de 2012 (ano em que o STF julgou a ADC No. 19/DF), os institutos despenalizadores previstos na Lei $\mathrm{n}^{\circ}$ 9.099/1995 foram aplicados aos casos de violência doméstica, apesar do advento da Lei $n^{\circ}$. 11.340/2006, cujo art. 41, proibia expressamente tal prática.
} 
nesta seara. De acordo com Maia (2020), na Vara de Violência Doméstica e Familiar Contra a Mulher ludovicense, com competência para processar e julgar ações penais, durante o recorte temporal da sua pesquisa, foi notável a grande incidência dos crimes de ameaça (485) e leão corporal (478), seguidos pela contravenção penal de vias de fato (119). É possível perceber a forte incidência do crime previsto no art. 147 do Código Penal: de um total de 916 (novecentos e dezesseis) ações penais examinadas pela pesquisadora, em 485 (quatrocentos e oitenta e cinco) delas, registrou-se a ocorrência do crime de ameaça, seja de forma isolada ou mesmo conjugado com outro delito.

Tal constatação confirma a tese de que a violência doméstica, em regra, se perpetua através de uma espiral ascendente, em que os crimes tidos como "menores" de violência e tendem a se agravar com o passar do tempo. O próprio IPEA (2018) adotou este entendimento e constatou, a partir da base empírica de dados reunidos no Atlas da Violência de 2018, que a mulher que se torna vítima fatal muitas vezes já foi alcançada por outras espécies de violência doméstica, sejam elas psicológicas, patrimoniais, sexuais ou físicas.

Neste contexto, a broken windows theory, dos americanos Wilson e Keling (1982), surge como uma opção de arcabouço lógico e teórico, capaz de subsidiar ações dos poderes públicos, voltadas não apenas para a prevenção, mas principalmente à repressão do start do ciclo da violência doméstica, que se não combatido em sua origem e de imediato, evolui para agravamentos que podem ser irreversíveis.

Para os autores, há relação entre desordem e criminalidade e, em maior perspectiva, entre a não repressão de pequenos delitos e a sua evolução para a criminalidade violenta, formulando a alegoria da janela da fábrica que é quebrada e que, permanecendo assim, passa a mensagem de que pode-se ir além dessa inocente ousadia, sem que maiores consequências aconteçam, porque ninguém se importa (WILSON; KELING, 1982).

Nesse passo, uma vez comprovada a ocorrência de violência doméstica habitual não há que se falar em possibilidade de proposta de suspensão condicional do processo. Esta seria

\footnotetext{
${ }^{8}$ A terminologia "crime menor", neste contexto, equivale à expressão "pequena/média criminalidade", utilizada por Gomes (1997). Referir-se a um crime como "menor" ou de "pequena/média criminalidade/ofensividade" não o desqualifica como delito. Trata-se apenas da utilização de um critério objetivo - a quantidade de pena cominada - fixado dirimir questões de ordem prática, como: fixação do rito processual, benefícios processuais, cálculo do prazo prescricional, etc.
} 
destinada para casos em que a violência fosse de pequena monta e isolado ou no início do ciclo de violência, aliada às hipóteses em que a vítima já voltou a conviver com o agressor de forma harmônica ou não tem mais nenhum tipo de contato com ele.

Certo é que, como Souza (2016) e Maia (2020) concluíram, os “crimes menores” são os que possuem prazo prescricional mais exíguo e, consequentemente, são os mais afetados pela prescrição penal. Isso significa que, em termos de violência doméstica, fechar as portas para as alternativas ofertadas pela justiça criminal consensuada, dentre as quais a suspensão condicional do processo se destaca, é o mesmo que privar a sociedade de testar uma ferramenta de efetividade, já que no modelo atual, na prática, não se pune, tampouco se permite a construção de solução consensual.

Diante desses aportes, a escolha do legislador no sentido de inserir a suspensão condicional no processo na Lei Maria da Penha teria que ser aceita pelo Supremo Tribunal Federal, pois, segundo Robert Alexy (2008, p. 591), “[...] o legislador tem uma prerrogativa de avaliação e decisão para a escolha entre diversos caminhos potencialmente adequados para alcançar um objetivo legal."

Finalmente, segundo Hübner (2011), é desejável que poderes desafiem uns aos outros, desde que articulem razões de melhor qualidade. Assim, embora se reconheça a autoridade da decisão proferida pelo STF na ADC 19-DF, a democracia tem a ganhar se a razão pública (padrão de argumentação moral que deve disciplinar a deliberação política) estimular a ação do Poder Legislativo para inserir na Lei Maria da Penha a possibilidade de suspensão condicional do processo.

\section{MECANISMOS IMPEDITIVOS DO DESVIRTUAMENTO PRÁTICO DA SUSPENSÃO CONDICIONAL DO PROCESSO NA SEARA DA VIOLENCIA DOMÉSTICA}

Para que não haja o risco do instituto da suspensão condicional do processo ser desvirtuado, tal qual supostamente ocorreu entre os anos de 1995 e 2012, a alteração proposta 
para o art. 41 da Lei Maria da Penha deve promover ressalvas que garantam o atendimento das especificidades que os casos que envolvem violência doméstica possuem.

Primeiramente, como já dito, a suspensão condicional do processo não pode ser admitida para casos em que for comprovada a existência de violência doméstica habitual, ou seja, quando a violência deixou de ser isolada ou estar no seu início e passou a se manifestar várias vezes.

De outra banda, em seu modelo original ${ }^{9}$, o ofendido não intervém na suspensão condicional do processo, já que ele não é o titular da ação penal. Alterando-se o art. 41 da LMP para permitir o referido benefício, a oitiva da vítima torna-se fundamental, assim como a obrigatoriedade da sua representação por advogado ou defensor público. O objetivo desta mudança é fazer com que o ponto de vista da ofendida tenha maior relevância na construção do consenso, sendo possível alcançar de forma mais efetiva a pacificação social.

Consoante Madureira (2018), a Advocacia e a Defensoria Pública, ao lado da Advocacia Pública e do Ministério Público, mereceram do constituinte tratamento normativo específico que se revela na sua inserção no Título IV da Constituição brasileira, que trata "Da organização dos Poderes, incluindo-os no Capítulo IV, consagrado às chamadas "Funções Essenciais da Justiça". Os advogados, explicita o autor, prestam serviço público e exercem função social ao serem contratados por clientes, formulando pretensão jurídica em favor destes ou veiculando argumentos de defesa capazes de sustentar a resistência de seus constituintes à pretensão deduzida pela parte adversária, bem como interpor recursos contra decisão do Judiciário. Quanto às atribuições dos defensores públicos, o teórico esclarece que consistem na franquia do acesso ao amparo da ordem jurídica em favou dos desvalidos de fortuna, prestando-lhe assistência jurídica integral e gratuita.

A formulação de um modelo de suspensão condicional do processo adequado para os casos de violência doméstica exige o protagonismo das equipes multidisciplinares, com a contribuição de conhecimentos de outras áreas, como o serviço social, a psicologia ou a medicina, a fim de melhor delinear as várias repercussões da violência doméstica na vida dos

\footnotetext{
${ }^{9}$ Ver art. 85, da Lei no ${ }^{\circ}$ 9.099/1995.
} 
envolvidos e dos seus familiares e colaborar com sugestões de condições ${ }^{10}$ ao benefício capazes de punir o agressor e, ao mesmo tempo, devolver um arranjo mais satisfatório à sociedade.

Por último, para que a suspensão condicional do processo se torne plenamente compatível com a Lei $\mathrm{n}^{\circ}$. 11.340/2006, é essencial a capacitação dos operadores das instituições do sistema de justiça (magistrados, Ministério Público, defensores públicos e advogados) para que estes entendam os delineamentos e as repercussões da violência doméstica como fenômeno social. Assim, as administrações superiores do Poder Judiciário, Ministério Público, Defensoria Pública e Ordem dos Advogados do Brasil devem comprometer-se a capacitar os seus profissionais e fornecer meios - materiais e humanos - para que estes possam desempenhar os seus papeis na construção de uma solução criminal consensual.

\section{CONSIDERAÇÕES FINAIS}

O presente estudo, de forma alguma, pretende exaurir o tema da aplicação da justiça criminal consensual aos crimes praticados no âmbito da violência doméstica. A intenção é promover a reflexão e discussão do tema, trazendo à luz argumentos favoráveis à mudança do parâmetro punitivo difundido nesta seara.

Muitos esforços foram empreendidos desde a publicação da Lei Maria da Penha até a atualidade, no entanto, pesquisas como as realizadas por Souza (2016) e Maia (2020) apontam para a disfuncionalidade do sistema de justiça criminal, que não consegue atender de forma eficiente e efetiva as demandas penais decorrentes da violência doméstica.

Nota-se o predomínio da lógica da "trivialização do conflito" vigente nas amostras empíricas representadas pelas referidas pesquisas, que denunciam o disparate entre a norma e a realidade. O crescente endurecimento da norma influenciado pelo discurso da sociedade de risco, o apequenamento do espaço para dos protagonistas (autor e vítima) dos delitos praticados sob os auspícios da violência, enquanto o poder judiciário preocupa-se em seguir uma marcha

${ }^{10}$ A exemplo disso, condições que imponham participação em grupos reflexivos para agressores domésticos, acompanhamento psicológico, reparação de danos, posse de bens, etc. 
burocrática disfuncional, voltada apenas para a concessão de uma solução formal, sem interesse na independência dos indivíduos.

Dentro deste contexto de baixa efetividade, de crises de legitimidade e eficiência, Giuliani (2014) defende que uma decisão criminal construída de forma negociada mostra-se mais aceita tanto pelas partes envolvidas, quanto pela sociedade e, portanto, mais facilmente cumprida, trazendo benefícios ao funcionamento do sistema como um todo, o que permite alcançar de forma mais satisfatória a pacificação social.

A solução que melhor se adequa a este cenário é a suspensão condicional do processo, mas não aplicada da forma prevista no art. 89, da Lei $n^{\circ}$. 9.099/1995. Para que o referido instituto seja adequado às especificidades dos crimes praticados sob os auspícios da violência doméstica, é necessário adaptá-lo e, assim, dispormos de uma alternativa às penas restritivas de liberdade, uma vez que a suspensão condicional do processo possui o condão de evitar a aplicação da pena, mas sem esvaziar o caráter ilícito da conduta típica, atribuindo ao acusado as mesmas condições do sursis além de outras de caráter específico.

A adequação proposta neste trabalho orienta à realização da oitiva da vítima e obrigatoriedade da sua representação por advogado ou defensor público, aumento do protagonismo das equipes multidisciplinares e capacitação de juízes, promotores de justiça, defensores públicos e advogados sobre os delineamentos e repercussões da violência doméstica como fenômeno social.

\section{REFERÊNCIAS}

ALEXY, Robert. Teoria dos direitos fundamentais. São Paulo: Malheiros, 2008.

BITENCOURT, Cezar Roberto. Juizados especiais criminais federais: análise comparativa das Leis n. 9.099/95 e 10.259/2001. São Paulo: Saraiva, 2005.

BOURDIEU, Pierre. A dominação masculina. Tradução Maria Helena Kühner. 11. ed. Rio de Janeiro: Editora Bertrand, 2012. 
BRAGA FILHO, Vladimir. Suspensão condicional da pena e suspensão condicional do processo: eficácia de cada um dos institutos. São Paulo: Editora J. H. Mizuno, 2006.

CARVALHO, Júlio César Leite de. Juizados especiais criminais: suspensão condicional do processo à Luz da Lei 9.099/95. 2.ed. rev. e atual. Curitiba: Juruá, 2010.

CARVALHO, Márcia Haydée Porto de. Instituição da Suspensão Condicional do Processo nos Casos de Violência Doméstica Contra a Mulher a partir da Alteração da Lei Maria da Penha: por uma alternativa menos rigorosa buscada na conciliação para enfrentar esse mal. In: ENCONTRO DE INTERNACIONALIZAÇÃO DO CONPEDI, 3., 2015. Anais eletrônicos [...] Madrid: CONPEDI, $2015 . \quad$ Disponível <https://www.indexlaw.org/index.php/conpedireview/article/view/3398/2914>. Acesso em: 15 fev. 2020.

GIULIANI, Emília Merlini. Mecanismos de Consenso no Direito Processual Penal Brasileiro e o Projeto de código de Processo Penal. In: SANTIADO, Nestor Eduardo Araruna; BORGES, Paulo César Corrêa Borges, SOUZA, Claudio Macedo de (coord.). Direito penal, processo penal e constituição. Florianópolis: CONPEDI/UFSC, 2014. Disponível em: <http://www.publicadireito.com.br/artigos/?cod=eb4ab9e8db10f6fd>. Acesso em: 22 fev. 2020.

GRINOVER, Ada Pellegrini et al. Juizados especiais criminais: comentários à Lei 9.099, de 26/09/1995. São Paulo: RT, 1995.

IPEA. Atlas da Violência 2019. Brasília, DF: IPEA, 2019. Disponível em: <http://www.ipea.gov.br/portal/images/stories/PDFs/relatorio_institucional/190605_atlas_da_ violencia_2019.pdf >. Acesso em: 20 fev. 2020.

GOMES, Luiz Flávio. Suspensão Condicional do Processo Penal e a Representação nas Lesões Corporais, sob a Perspectiva do Novo Modelo Consensual de Justiça Criminal. 2. ed., atual. e ampl. São Paulo: Editora Revista dos Tribunais, 1997.

MADUREIRA, Claudio. Advocacia, Advocacia Pública e Defensoria Pública. In: ALVIM, Eduardo Arruda; STRECK, Lenio (coord.). Curso de direito constitucional. Florianópolis: Tirant lo blanch, 2018.

MAIA, Maicy Milhomem Moscoso. Prescrição e Efetividade: análise das ações penais de competência da Vara de Violência Doméstica e Familiar Contra a Mulher de São Luís (2014 2018). 341 f. 2020. Dissertação (Mestrado em Direito e Instituições do Sistema de Justiça) Universidade Federal do Maranhão, São Luís, 2020. Disponível em: <http://tedebc.ufma.br:8080/jspui/handle/tede/3051>. Acesso em: 15 fev. 2020.

MARMOR, Andrei. Interpretation and legal theory. Revised second edition. Oregon: Oxford and Portland, 2005.

MENDES, Conrado Hübner. Direitos fundamentais, separação de poderes e deliberação. São Paulo: Saraiva, 2011. 
MIRABETE, Júlio Fabbrini. Juizados especiais criminais. São Paulo: Atlas, 1997.

SAFFIOTI, Heleyeth I. B.; ALMEIDA, Suely Souza de. Violência de Gênero: poder e impotência. Rio de Janeiro: Editora Revinter, 1995.

SOUZA, Luanna Tomaz de. Da expectativa à realidade: a aplicação das sanções na Lei Maria da Penha. 1. ed. Rio de Janeiro: Editora Lumen Juris, 2016.

WILSON, James Q.; KELLING, George L. Broken Windows. The police and neightborhood safety. The Atlantic, mar. 1982.

Data de Submissão: 27/03/2020

Data de Aceite: $31 / 03 / 2020$ 